\title{
Identification and quantification of Cinnamomum camphora seeds extract and development of citric acid and polyphenols based carboxymethyl chitosan-gum Arabic hybrid film for intelligent packaging applications
}

\author{
Fawze Alnadari \\ Nanjing Agricultural University - Weigang Campus: Nanjing Agricultural University \\ Anthony Pius Bassey \\ Nanjing Agricultural University - Weigang Campus: Nanjing Agricultural University \\ Mohamed Abdin \\ Nanjing Agricultural University - Weigang Campus: Nanjing Agricultural University \\ Mohamed Abdelbaset Salama \\ Agricultural Research Center \\ Mustapha Muhammad Nasiru \\ Nanjing Agricultural University - Weigang Campus: Nanjing Agricultural University \\ Zhuqing Dai \\ Jiangsu Academy of Agricultural Sciences \\ Yuhang $\mathrm{Hu}$ \\ Nanjing Agricultural University - Weigang Campus: Nanjing Agricultural University \\ Xiaoxiong Zeng ( $\square$ zengxx@njau.edu.cn ) \\ Nanjing Agricultural University - Weigang Campus: Nanjing Agricultural University https://orcid.org/0000-0003-2954-3896
}

\section{Research Article}

Keywords: Polyphenols, Citric acid, Edible film, Antioxidant, Antimicrobial, Active packaging

Posted Date: February 22nd, 2022

DOI: https://doi.org/10.21203/rs.3.rs-1326648/v1

License: () (1) This work is licensed under a Creative Commons Attribution 4.0 International License. Read Full License 


\section{Abstract}

In this study, carboxymethyl chitosan with gum Arabic (CG) based novel functional films containing Cinnamomum camphora seeds extract (CCSE) at varying concentrations $(0.5,1.2$ and $2 \%$ in $w / w)$ were successfully fabricated. Moreover, sixteen phenolic compounds were identified by LC-ESI-QTOF-MS and the most abundant organic acid was citric acid (present at $1062.55 \mu \mathrm{g} / \mathrm{g} \mathrm{dry}$ weight in CCSE). SEM showed that higher extract concentration indicated a homogeneous surface and more stability of films. CCSE inclusion into CG resulted in a marked increase (33.01 to $63.23 \mathrm{MPa}$ ) of tensile properties, with optimum thickness. The swelling degree, water solubility, and water vapor permeability were markedly $(p<0.05)$ reduced from 54.21 to $31.70 \%, 32.05$ to $14.02 \%$, and 3.46 to $1.12 \times 10^{-11} \mathrm{~g}^{-1} \mathrm{~s}^{-1} \mathrm{~Pa}^{-1}$, respectively. The open control and CG samples showed much higher peroxide values of sunflower oil ( $69.49 \pm 0.68$ and $20.15 \pm 0.31 \mathrm{mEq} / \mathrm{kg}$, respectively) while CG-CCSE2 exhibited a low value $(9.79 \pm 0.28 \mathrm{mEq} / \mathrm{kg})$ after 28 days incubation. The good antioxidant and antimicrobial properties exhibited by the fabricated films demonstrated their potential use in the food packaging industry.

\section{Introduction}

About 39000 to 52000 consumption of micro-plastic particles by humans is recorded annually [1]. Many environmental problems were happened due to the unending utilization of petroleum-based plastic materials because of their non-degradable nature [2]. Consequently, the accumulation of these plastic materials in landfills or oceans induces eco-pollution [3], thereby posing health risks to consumers. To ameliorate this environmental concern, new food packaging films have been developed by researchers from various biopolymers such as polysaccharides, lipids, and proteins. Due to their suitable characteristics like vapor and water barrier [4], the potential application of these materials in food preservation as alternative packaging sources is imperative. Importantly, positive comments have been received for bio-based films as a biodegradable substance and also as a carrier of bioactive substances $[5,6]$.

Green active packaging is an innovative technology that has appeared as an enticing alternative for the food packaging film, which contains bioactive compounds including antimicrobials and antioxidants [7]. Several natural ingredients such as tea polyphenols [8], chives root extract [9], red grape extract [10], sweet potato extract [11], mango peel extract [7], thyme, mango kernel, murta leaf and grape seed extracts [12] have been reported to enhance the antioxidant efficacy of bio-based films. The vast amount of wastes generated from the processing of fruits and vegetables can be utilized as potential polyphenol sources and other bioactive compounds [13].

Carboxymethyl chitosan (CMC) is a promising biocompatible and biodegradable polymer produced from chitosan reaction with mono-chloroacetic acid under alkaline conditions [14]. Gum Arabic (GA), a negatively-charged heteropolysaccharide derived from the branches of Acacia tree trunks, has been distinguished as ideal for use in oil-in-water emulsion systems following its encapsulation and emulsification potentials $[15,16]$. Additionally, the polyelectrolytic property in the presence of uronic acid enables its use as encapsulation carriers of active components by simple or complex polyelectrolyte complexes [17]. Through electrostatic interactions, polyanionic GA can form characteristic composites with polycationic polymers like $\mathrm{CMC}$, with the complexes exhibiting different behaviors in different mass ratios [18]. Though the attempt to apply CMC and GA in food packaging has been studied, their low antioxidant and antimicrobial potential make them undesirable and inefficient food packaging $[19,20]$. Therefore, to mitigate these constraints, numerous natural plants possessing potent bioactivities, including quercetin [21], propolis extract [22], pullulan [23], polyphenols extracted [24], protein isolate extracted [25], and seed cover extract [26] have been incorporated into CMC and GA film. Cinnamomum camphora tree belongs to the Lauraceae family. It is widely grown as a landscape tree in Southern China and abundant in Korea, Vietnam, Japan, and India across tropical and subtropical zones. C. camphora seeds are abundant, with a yearly yield exceeding 1 million tons in China [27]. The seeds of the tree are not only used for oil extraction but also to treat various ailments [28]. The health benefits and biological functions of $C$. camphora seeds are mostly associated with their polyphenolic contents [29]. Previous studies have also indicated that $C$. camphora seeds consist of approximately $58.02 \%$ crude fat, $18.15 \%$ crude protein, $17.9 \%$ carbohydrate, $3.97 \%$ moisture, and $1.96 \%$ ash [27]. In China, the seeds are often used in almost every extraction oil and traditional Chinese medicine, thereby generating huge residues in the form of seeds $[30,31]$. The polyphenols of $C$. camphora seeds extract (CCSE) have also been known to possess antimicrobial and antioxidant properties [32]. Therefore, LC-ESI-QTOF-MS was applied to identify polyphenols and organic acids in CCSE. Sixteen phenolic compounds were identified, and the most abundant phenolic compounds were 4-hydroxybenzoic acid and 
p-coumaric acid. Due to this, the exploration of CCSE as a potent component for developing CG-based active packaging film should be considered. Thus, this study was designed to explore the effect of CCSE as an active ingredient to produce CMC with GA active food packaging film and to estimate the structural, mechanical, biological and physical activities of the produced films. Furthermore, the produced film was examined as a potential packaging material for oil storage in the food industry.

\section{Materials And Methods}

\subsection{Materials and reagents}

The seeds of $C$. camphora were collected in the ripening stage from the trees growing at Nanjing Agricultural University (Nanjing, China). Analytical grade standards of protocatechuic acid, gentisic acid, phlorizin, 4-hydroxybenzoic acid, procyanidin B3, citric acid, $p$-coumaric acid, syringic acid, L-ascorbic acid, ferulic acid, caffeic acid, salicylic acid, quercetin, rutin, catechin and epicatechin were purchased from Henan Putian Tongchuang Biotechnology Co., Ltd. (Henan, China). CMC was obtained from Junsei Chemical Co., Ltd. (Tokyo, Japan), while glycerol was obtained from Solarbio Science and Technology Co., Ltd. (Beijing, China). 2,2-Diphenyl-1-picrylhydrazyl (DPPH) and 2,2'-azino-bis-(3-ethylben-zothiazoline-6-sulphonic acid) (ABTS) were obtained from Sigma Chemical Co., Ltd. (St Loius, MO, USA). Gallic acid was purchased from Aladdin Industrial Inc. (Shanghai, China). The sunflower oil was obtained from a local market (Nanjing, China,). All other reagents used were of analytical grade.

\subsection{Preparation and purification of CCSE}

The extraction experiments were designed as follows: first, seed coats were peeled from fresh fruits of $C$. camphora and ovendried for $12 \mathrm{~h}$ at $50{ }^{\circ} \mathrm{C}$. To remove oil from seeds, the crushed $C$. camphora seeds $(25 \mathrm{~g})$ were continuously extracted with $150 \mathrm{~mL}$ petroleum ether at $45{ }^{\circ} \mathrm{C}$ for $6 \mathrm{~h}$ in a Soxhlet apparatus. Afterward, the crushed seeds were ground to powder and extracted with $80 \%$ aqueous ethanol solution at $45^{\circ} \mathrm{C}$ for $90 \mathrm{~min}$, with ultrasonication at $300 \mathrm{~W}$ (KQ 300DB, $300 \mathrm{~W}, 0-40 \mathrm{kHz}$, Kunshan Ultrasonic Instrument, Kunshan, China). After vacuum filtration, the supernatants were obtained and concentrated at $45^{\circ} \mathrm{C}$ by a vacuum rotary evaporator. The targeted phase was then loaded onto a column $(5 \times 30 \mathrm{~cm})$ of D101 resin, washed with distilled water at a flow rate of $1.5 \mathrm{~mL} / \mathrm{min}$ to eliminate strongly polar components. After that, the column was eluted twice with $80 \%$ ethanol. The resulting elution was concentrated by a rotary evaporator at $45^{\circ} \mathrm{C}$ and freeze-dried to obtain purified fractions of CCSE.

\subsection{Characterization of phenolic compounds in CCSE 2.3.1. Total phenolic content}

The Folin-Ciocalteu method outlined by Islam et al. [33] was adopted to evaluate the total polyphenol content of CCSE. Briefly, 0.5 $\mathrm{mL}$ from the sample was added to $1.0 \mathrm{~mL}$ from the reagent (Folin-Ciocalteu) was diluted 10 times and left in the dark for 6 min. After that, $2.5 \mathrm{~mL}$ from $\mathrm{Na}_{2} \mathrm{CO}_{3}(75 \mathrm{~g} / \mathrm{L})$ was added and the mixture was kept for $30 \mathrm{~min}$ at $25^{\circ} \mathrm{C}$. At $765 \mathrm{~nm}$, the absorbance of the sample was measured, and the amount of total phenolic content was expressed as mg of gallic acid equivalent (GAE) per $\mathrm{g}$ of extract. Gallic acid was used as a standard for plotting the calibration curve. All experiments were repeated six times.

\subsubsection{LC-ESI-QTOF-MS analysis}

Identification and quantification of polyphenols in CCSE were achieved by the LC-ESI-QTOF-MS system (G2-XS QTOF Waters, Manchester, UK). In brief, the extract was prepared at a concentration of $5 \mathrm{mg} / \mathrm{mL}$. After that, the samples were centrifuged at $3,000 \mathrm{rpm}$ (Beckman coulter Avanti J-265XP) for $15 \mathrm{~min}$ at $20^{\circ} \mathrm{C}$. Continuously, $1.5 \mathrm{~mL}$ of supernatants were collected in HPLC vials for LC-MS, and $2 \mu \mathrm{L}$ solution was injected into the UPLC column $(2.1 \times 100 \mathrm{~mm}, 1.7 \mu \mathrm{m}$ particles, ACQUITY UPLC BEH C18 column) with a flow rate of $0.3 \mathrm{~mL} / \mathrm{min}$. Buffer A consisted of $0.1 \%$ formic acid in the water, and buffer B consisted of $0.1 \%$ formic acid in acetonitrile. The gradient was $5 \%$ Buffer B for $0.5 \mathrm{~min}, 5-95 \%$ buffer B for $11 \mathrm{~min}, 95 \%$ buffer B for 2 min. Electrospray ionization (ESI) was used as a source in positive modes with a preferred mass spectrum in the $m / z$ range 100-1600. The leucineenkephalin ( $m / z 556.2771)$ was used for recalibration and removing the lock mass. Ionization parameters were the following: the capillary voltage was $2.5 \mathrm{kV}$, sample cone was $40 \mathrm{~V}$, source temperature was $120^{\circ} \mathrm{C}$ and desolvation gas temperature was $800{ }^{\circ} \mathrm{C}$. Data acquisition and processing were performed using Masslynx software version 4.1.

\subsubsection{HPLC analysis of CCSE}


Aglient 1100 Series HPLC system (USA) with DAD detector and Phenomenex SynergiTM $4 \mu \mathrm{m}$ RP-Hydro C-18 $(0.46 \times 250 \mathrm{~mm})$ was used to determine the phenolic composition of CCSE. Two mobile phases were used, formic acid in deionized water $0.1 \%$ $(\mathrm{v} / \mathrm{v})(\mathrm{A})$ and acetonitrile (B). The flow rate was set at $15-30 \%$ from 0 to10 $\mathrm{min}, 30-50 \%$ from 10 to $15 \mathrm{~min}, 50-60 \%$ from 15 to 20 min, and $60-70 \%$ from 20 to $25 \mathrm{~min}$, and $70-80 \%$ from 25 to $30 \mathrm{~min}$. The injection volume and the flow rate were $20 \mu \mathrm{L}$ and 0.35 $\mathrm{mL} / \mathrm{min}$, respectively. The samples were measured at $280 \mathrm{~nm}$ and the column temperature was $35^{\circ} \mathrm{C}$.

\subsection{Preparation of films}

The films were fabricated by dissolving 6.0 and $3.2 \mathrm{~g}$ of CMC and GA, respectively, in distilled water ( $400 \mathrm{~mL})$. After stirring (800 $\left.\mathrm{rpm}, 60^{\circ} \mathrm{C}, 2 \mathrm{~h}\right)$, the glycerol solution $(35 \% \mathrm{w} / \mathrm{w}$ based on CMC and GA used), used as a plasticizer, was added to the mixture and thoroughly homogenized by stirring at $800 \mathrm{rpm}$ at $50{ }^{\circ} \mathrm{C}$ for $30 \mathrm{~min}$. After that, CCSE was added at the concentration of $0,0.5,1.2$ and $2 \%$ (based on CMC and GA used) to afford groups of CMC/GA (CG, control), CMC/GA with the respective concentrations denoted as (CG-CCSE 0.5, CG-CCSE 1.2, and CG-CCSE 2), respectively. Every group was stirred $\left(40{ }^{\circ} \mathrm{C}, 800 \mathrm{rpm}, 1 \mathrm{~h}\right)$ to afford a thorough blend. Afterward, $50 \mathrm{~mL}$ aliquot from each group was carefully poured into petri-dish plates (150 mm) and oven-dried (45 ${ }^{\circ} \mathrm{C}, 12 \mathrm{~h}$ ). The films were then peeled off the plates and stored in a desiccator at $30^{\circ} \mathrm{C}$ until further analysis.

\subsection{Characterization and mechanisms of films}

\subsubsection{Scanning electron microscopy (SEM) analysis}

The surface morphology of produced films was analyzed using SEM (SU8010, Hitachi, Japan) at $10 \mathrm{kV}$. The films were cut (10 × $10 \mathrm{~mm}$ ) and placed on an aluminum slab using a double-sided sputter covered with gold and carbon tape.

\subsubsection{FT-IR spectrophotometry analysis}

FT-IR spectrometry (Nicolet iS-50, Thermo, USA) with 4000 to $525 \mathrm{~cm}^{-1}$ frequency range was employed to analyze the prepared film's initial structures.

\subsubsection{X-ray diffraction (XRD)}

An X-ray diffractometer (D8 Advance, Bruker, USA) was used to identify the crystal structure of the films at $30 \mathrm{kV}$ and $10 \mathrm{~mA}$. Angular range $\left(2 \theta=5-80^{\circ}\right)$ was applied to detect the scattered radiation at $15.6^{\circ} / \mathrm{min}$ scanning speed.

\subsubsection{Differential scanning calorimetry (DSC) analysis}

DSC (DSC-60, Shimadzu Corp., Kyoto, Japan) was used to analyze the thermal properties of the films. Briefly, 10 mg of film pieces were sealed in a standard aluminum pan which was heated under a nitrogen atmosphere from 27 to $450{ }^{\circ} \mathrm{C}$ at a rate of $10{ }^{\circ} \mathrm{C} / \mathrm{min}$

\subsubsection{Thickness and mechanical properties analysis}

The film thickness was estimated by a digital hand-held micrometer (Mitutoyo Absolute, Tester Sangyo Co. Ltd., Japan). Each sample was measured 10 times randomly at various levels, and the mean was calculated. Additionally, a texture analyzer (TA.XT Plus, Stable Micro Systems Ltd., Surrey, UK) was employed to analyze the mechanical properties (tensile strength percentage (TS) and elongation-at-break (EB) of the films at room temperature. Film strips $(10 \times 80 \mathrm{~mm})$ were positioned on grips $(50 \mathrm{~mm})$ with the tensile power and cross speed processed at $5 \mathrm{kN}$ and $50 \mathrm{~mm} / \mathrm{min}$, respectively. The films were examined three times. TS and EB values, per the values of extensibility $(\mathrm{mm})$ and resistance to extension $(\mathrm{N})$, were calculated using the equation.

$$
\begin{aligned}
T S(M P a) & =\frac{F}{X \times W} \times 100(1) \\
E B(\%) & =\frac{\Delta L}{L} \times 100(2)
\end{aligned}
$$

Where $F=$ resistance to extension $(\mathrm{N}), \mathrm{X}=$ film thickness $(\mathrm{mm})$ and $\mathrm{W}=$ the width of the film $(\mathrm{mm}), \Delta \mathrm{L}=$ the increase in the distance at the break $(\mathrm{mm})$ and $L=$ the original length between grips of the film $(\mathrm{mm})$.

\subsubsection{Measurements of solubility, swelling ratio and moisture}


The film bands $(20 \times 20 \mathrm{~mm})$ were weighted as wet weight $\left(\mathrm{M}_{0}\right)$ and dried at $105{ }^{\circ} \mathrm{C}$ till constant weight to calculate the primary dry mass value $\left(M_{1}\right)$. The dried pieces were transferred to $100 \mathrm{ml}$ beakers filled with distilled water $(50 \mathrm{~mL})$ covered with plastic wraps and preserved at $25^{\circ} \mathrm{C}$ for $24 \mathrm{~h}$. Next, the films were dehydrated superficially with filter papers and weight to get $\left(M_{2}\right)$. The saturated-hydrate films were dehydrated again to constant weight at $105^{\circ} \mathrm{C}$ to afford final dry mass $\left(\mathrm{M}_{3}\right)$. The moisture content (MC), swelling ratio, and solubility were measured using the equation below.

$$
\begin{gathered}
\text { Moisturecontent(\%) }=\frac{M_{0}-M_{1}}{M_{0}} \times 100(3) \\
\text { Swelingratio(\%) }=\frac{M_{2}-M_{0}}{M_{0}} \times 100(4) \\
\text { Filmsolubility(\%) }=\frac{M_{1}-M_{3}}{M_{1}} \times 100(5)
\end{gathered}
$$

Where $M_{0}$ = initial weight of the film, $M_{1}$ = initial dry weight of the film, $M_{2}=$ weight after drenching films in water for $24 h$, and $M_{3}$ = dry weight of the film after drenching films in water for $24 \mathrm{~h}$.

\subsubsection{Analysis of water vapor permeability (WVP) of films}

The method of Zhang et al. [34] was followed to estimate the WVP values of the films with minor changes. The film samples (5x $5 \mathrm{~cm}$ ) and anhydrous $\mathrm{CaCl}_{2}$ were loaded in special glass cups $(4 \mathrm{~cm})$ and sealed. After that, the cups were placed in a desiccator at $75 \%$ humidity and packed with sodium chloride saturated solution. Thereafter, for $10 \mathrm{~h}$, the weight of the cups was recorded each hour and after $24 \mathrm{~h}$. By using linear regression, the slope of weight difference against time was recorded against time. The WVP $\left(\mathrm{g} \mathrm{m}^{-1} \mathrm{~s}^{-1} \mathrm{~Pa}^{-1}\right)$ was estimated as follows:

$$
W N P=\frac{\text { Slope } \times L}{A \times \Delta P}(6)
$$

where $L=$ average film thickness $(m), A=$ transfer area $\left(m^{2}\right)$, and $\Delta P=$ difference in the pressure of partial water vapor.

\subsubsection{Film color and opacity}

The color of films was measured using a colorimeter (CR-40, Minolta, Camera Co., Japan) with illuminant D65, a $0^{\circ}$ viewing angle, and a $0.13 \mathrm{~mm}$ diameter viewing area was used to determine the color of prepared films. Before measurement, the Colorimeter was calibrated with a white tile ( $\bmod \mathrm{CR}-\mathrm{A} 43)$. The equations below were used to estimate the total color variation $(\Delta \mathrm{E})$, white $(\mathrm{WI})$ and yellow (YI) indexes.

$$
\begin{gathered}
\Delta E=\left(\left(L_{i}^{*}-L^{*}\right)^{2}+\left(a_{i}^{*}-a^{*}\right)^{2}+\left(b_{i}^{*}-b^{*}\right)^{2}\right)^{1 / 2}(7) \\
Y I=\frac{142.68 \times b^{*}}{L^{*}}(8) \\
W I=100-\left(\left(100-L^{*}\right)^{2}+a^{* 2}\right)^{1 / 2}+b^{* 2}(9)
\end{gathered}
$$

UV-722 spectrophotometer (Shanghai Jinghua Science \& Technology Instruments Co., Ltd., China) was used to determine the opacity of the samples at $600 \mathrm{~nm}$. The transparency for the sliced bands $(80 \times 45 \mathrm{~mm}$ length) was assessed. The opacity was calculated as equated below.

$$
\text { Opacity }=A / L(10)
$$

Where, $A=$ absorbance value at $600 \mathrm{~nm}$ and $L=$ film thickness $(\mathrm{nm})$

\subsubsection{Determination of the antioxidant activity of films}


The method outlined by Liu et al. [35] was employed to determine the antioxidant activity of the films. Film solution (50 $\mu \mathrm{L})$ was mixed with $200 \mu \mathrm{L}$ of working solution from ABTS, the absorbance at $734 \mathrm{~nm}$ was measured, and scavenging activity was estimated as shown below.

$$
\text { ScavengingactivityonABTSfreeradicals }(\%)=\left(1-\frac{A_{1}-A_{2}}{A_{0}} \times 100\right)
$$

Where $A_{o}=A B T S^{+}$initial absorbance, $A_{1}=$ sample absorbance, and $A_{2}=$ sample with PBS absorbance .

To determine the DPPH radical scavenging activity, $50 \mu \mathrm{L}$ from the film sample was blended with $200 \mu \mathrm{L}$ of DPPH methanolic solution $(0.2 \mathrm{mM})$ and put in the dark for $30 \mathrm{~min}$ at $30^{\circ} \mathrm{C}$. Later, the absorbance was measured at $517 \mathrm{~nm}$ with ascorbic acid used as the control. The scavenging activity was calculated as follows.

$$
\text { ScavengingactivityonDPPHfreeradicals(\%) }=\left(1-\frac{A_{1}-A_{2}}{A_{0}} \times 100\right)
$$

Where $A_{0}=$ initial DPPH absorbance, $A 1$ = sample absorbance, and $A 2$ = sample absorbance with water.

\subsubsection{Assay of antimicrobial activity of films}

The procedure of Khalid et al. [36] was employed to evaluate the antimicrobial activity of the prepared films against Gram-negative (Escherichia (E.) coli CGMCC 1.8721) and two Gram-positive (Staphylococcus (S.) aureus (CGMCC 1.8721) and Bacillus (B.) cereus (CGMCC 1.895)) bacteria. Briefly, each bacterial culture was diluted to afford a final $10^{5} \mathrm{CFU} / \mathrm{mL}$ concentration. The cells $(0.1 \mathrm{~mL})$ were spread onto a new medium agar plate. Subsequently, the discs of films (12 $\mathrm{mm}$ diameter) were prepared, sterilized under UV light, placed carefully in petri-dish plates, and incubated $\left(37^{\circ} \mathrm{C}, 24 \mathrm{~h}\right)$. A sliding caliper was used to estimate the area of the inhibitory zones.

\subsubsection{Biodegradation test}

The composting test described by Tan et al. [37] was adopted to analyze the biodegradation capacity of the prepared films. Briefly, the soil was collected from the experimental area at Nanjing Agricultural University (Nanjing, China). It was then put in a tray made from plastic and buried with the films $(2 \times 2 \mathrm{~cm})$ at $4 \mathrm{~cm}$ depth for 21 days. The soil was treated twice daily with water. Each week, the films were removed and their weight loss calculated using the following equation:

$$
\operatorname{Weightloss}(\%)=\frac{M_{0}-M_{1}}{M_{0}} \times 100(13)
$$

Where $M_{0}=$ initial film weight and $M_{1}=$ film weight after 7,14 , or 21 days of biodegradation.

\subsection{Experiments of packaging of sunflower oil 2.6.1. Capability of films for oil resistance}

The procedure of Wang et al. [38] was adopted to determine the capability of films for oil resistance with minor changes. Briefly, Whatman No. 1 filter paper $\left(6 \mathrm{~cm}\right.$ diameter) was dried in the hot-air oven at $50{ }^{\circ} \mathrm{C}$. The films $(4 \times 4 \mathrm{~cm})$ were then fitted with ropes above $5 \mathrm{~cm}$ of oil-containing glass test tubes and positioned downward for $48 \mathrm{~h}$ on the filter paper. Afterward, the weight was recorded, and the oil absorption ratio (OAR) was measured.

$$
O A R(\%)=\left(\frac{m}{m_{0}}-1\right) \times 100(14)
$$

Where $m=$ filter paper weight after $48 \mathrm{~h}$ and $m_{0}=$ weight of dried filter paper. 


\subsubsection{Determination of peroxide value (POV)}

Sunflower oil $(10 \mathrm{~mL})$ was added into a glass test tube $(15 \mathrm{~mm} \times 150 \mathrm{~mm})$ and samples containing sunflower oil were sealed and stored for 28 days at $50{ }^{\circ} \mathrm{C}$. From each sample, $10 \mathrm{~mL}$ was taken on days 1, 7, 14, and 28 to determine the POV by iodometric titration as outlined by the National Standard of the People's Republic of China GB/ T5009.227-2016 [39] with slight changes. Briefly, sunflower oil $(7.0 \mathrm{~mL})$ was dissolved in $30 \mathrm{~mL}$ of 2:3 (v/v) acetic acid and trichloromethane before adding $1.0 \mathrm{~mL}$ saturated potassium iodide and shaken in the dark for $1 \mathrm{~min}$. Afterward, distilled water $(30 \mathrm{~mL})$ was added and shaken for 1 min before adding starch indicator $(1 \%, 0.5 \mathrm{~mL})$ into the mix. The solution was titrated with $0.01 \mathrm{~N}$ sodium thiosulfate until the blue color disappeared, and the consumption rate was recorded. POV $(\mathrm{mEq} / \mathrm{kg})$ was calculated as shown below:

$$
P O V(\mathrm{mEq} / \mathrm{kg})=\frac{V \times N \times 1000}{W}(15)
$$

Where $V$ = volume of sodium thiosulfate for titration $(\mathrm{mL}), \mathrm{N}=$ normality of thiosulfate, and $\mathrm{W}$ = weight of the lipid $(\mathrm{g})$.

\subsection{Statistical analysis}

The SPSS 16.0 software was employed to analyze the data. One-way analysis of variance (ANOVA) was applied to determine the difference between factors and levels. Duncan multiple range tests were used to determine the significant differences $(p<0.05)$ between means.

\section{Results And Discussion}

\subsection{Characterization of phenolic compounds}

The total phenolic content of $C$. camphora seeds was $40.16 \pm 1.44 \mathrm{mg}$ of GAE/g of extract. The $C$. camphora seeds extract showed a fair amount of phenolic content, which is consistent with previous results [29,32]. Moreover, citric acid and 4hydroxybenzoic acid were mainly in CCSE. This observation also supported the results of LC-ESI-QTOF-MS. These observations illustrate that seed waste is a valuable source of citric acid that can be used not only to increase bioactivity but also to generate biodegradable food packaging films based on CG.

An untargeted qualitative analysis of phenolic compounds in CCSE was done by LC-ESC-QTOF/MS. Polyphenols in both positive and negative ionization modes were tentatively described based on their $m / z$ value from MS spectra. Table 1 displays all the compounds found in the seeds extract of $C$. camphora. A total of 16 phenolic compounds and citric acid were identified in $C$. camphora seeds (Table 1), they were mainly phenolic acids (8) and flavonoids (6) followed by other polyphenols, including hydroxycinnamic acids, hydroxybenzoic acids, flavones and flavanols. CCSE displayed citric acid and two polyphenolic compounds (4-hydroxybenzoic and p-coumaric acids) which lead to variation in organic acids, flavonoids, phenolic acids, other polyphenols and overall antioxidant activity [29, 32].

\subsection{Characterization of films properties}

\subsubsection{Observation of film microstructure by SEM}

The structure, homogeneity, and morphology of the matrix are very integral in the non-permeability of films [40]. SEM was employed to analyze the film microstructures, surface smoothness, voids, layer structure, and homogeneity. The surface images and cross-sections of control and CCSE-treated films were screened (Fig. 1A and B). The SEM images indicated that GA surfaces in the composite film impacted the CMC structure in the CG control film, causing discontinuities in the matrix of the polymer. However, the presence of CCSE enhanced the smoothness, uniformity, and homogeneity in the structures without bubbles or pores. At low concentration (CG-CCSE 0.5\%), dispersion of most of the compounds was done uniformly in the matrix without vivid aggregation, while in high CCSE concentration (CG-CCSE 1.2 and 2\%), the surface became more homogenous with lighter spots which might be synonymous to increase in films stability. Besides, the aggregation characteristics also enhanced the softness of CCSE-treated films (Fig. 1C), which induced tensile strength and lower transmittance values of films compared to the control group. The hydrophilicity of polyphenolic compounds present in the extract might be the reason for this. The attained results were 
comparable to the findings reported by Cheng et al. [41] and Dou et al. [42] when CG and sodium alginate films were prepared combined with different phenolic extracts. This observation also supported the results of FT-IR, mechanical properties, and DSC in the subsequent experiments.

\subsubsection{FT-IR observation}

FT-IR spectroscopy was performed to explore the intermolecular changes of the films (Fig. 2). The spectral bands of every film appeared around $3281.28 \mathrm{~cm}^{-1}$ for $0-\mathrm{H}$ stretching, 2936.57 and $2885.95 \mathrm{~cm}^{-1}$ for stretching from the alkyl group and peaked at $1589.05,1036.06$, and $919.87 \mathrm{~cm}^{-1}$ corresponded to $\mathrm{C}=\mathrm{O}, \mathrm{N}-\mathrm{H}$ bending vibration, $\mathrm{C}=\mathrm{N}$ stretching and $\mathrm{C}-\mathrm{O}-\mathrm{C}$ band stretching (Fig. 2A), respectively [9]. The CCSE spectrum indicated principal points at $3264.89,1609.78$, and $1177.81 \mathrm{~cm}^{-1}$ wavelengths, representing $\mathrm{O}-\mathrm{H}, \mathrm{COO}$ - (symmetric) and $\mathrm{C}-\mathrm{O}-\mathrm{C}$ stretching (Fig. 2B), respectively [23], while that of CMC displayed principal points in wavenumber length around $3291.89,1590.02,1419.83$, and $1053.42 \mathrm{~cm}^{-1}$, characterized of $\mathrm{O}-\mathrm{H}, \mathrm{COO}$ - (asymmetric), COO(symmetric), and C-O-C stretching, respectively. Akhtar et al. [4] also detected the stretching vibration of aliphatic C-H at 2899.93 $\mathrm{cm}^{-1}$. The spectral bands $\left(1413.56\right.$ and $\left.1600.14 \mathrm{~cm}^{-1}\right)$ of GA were consistent with the asymmetric and symmetric stretching vibration of -COO-, respectively [43]. The spectral band $\left(3292.85 \mathrm{~cm}^{-1}\right)$ denoted $\mathrm{O}-\mathrm{H}$ stretching of the glucosidic ring, while $2922.11 \mathrm{~cm}^{-1}$ signified C-H stretching [44]. To form CG control film, the addition of GA to CMC caused shifting in wavelength values compared with CMC and GA from 3506.91 to $3006.48 \mathrm{~cm}^{-1}$ to create a tough absorption band at $3276.46 \mathrm{~cm}^{-1}$ for $0-\mathrm{H}$ stretching. Additionally, a new peak $\left(2897.52 \mathrm{~cm}^{-1}\right)$ which did not appear in CMC or GA spectrum, indicating a potential occurrence of a cross-linked reaction between CMC and GA. It was evident from the spectral peaks after CCSE addition to the CG film that no covalent bond existed between CG and CCSE, demonstrating only physical interaction between them. Also, the shifting of the low wavenumber of some peaks was dose-dependent. This could be related to CCSE in CG, which, due to intermingling with the glycerol-polymer matrix, modified the $\mathrm{OH}$ group's availability within the polymer network. These results are similar with the previous findings [45].

\subsubsection{Observation by XRD}

For the evaluation of the crystalline structure and effect of CCSE inclusion in CG film, XRD analysis was employed. As observed, CG possessed an amorphous structure with a wider and single peak at $2 \theta$ about $20^{\circ}$ (Fig. 3A), corroborating the findings of Wu et al. [23]. This indicated that CCSE incorporation did not affect the inner structure of the CG control films. Also, the X-ray spectrum of films following CCSE inclusion only reduced the strength of spectral peaks, being wider with increasing CCSE concentration. This phenomenon was aided because the interaction between CG and CCSE facilitated the formation of hydrogen bonds in CG, causing a decline in crystallinity. Therefore, the mechanical characteristics of a film depend significantly on the crystallites in its structure. Similarly, Riaz et al. [46] discovered the crystallinity of carboxymethyl cellulose film raised after adding polyphenols from Chinese chives (Allium tuberosum), which could be connected with the retrogradation of carboxymethyl cellulose that appeared through film preservation. In CG-CCSE films, because of the competitive effect of hydrogen bonds between CG and CCSE, their interactions could hinder the formation of inter-and intra-molecular hydrogen bonds in CG, thereby inducing a decline of crystallinity. These findings were consistent with a recent study [43].

\subsubsection{DSC analysis}

As displayed in Fig. 3B, DSC analysis was performed to determine the treated film thermal transition, and evaluate the possible changes in the film crystallinity. Except for CG-CCSE 2, which exhibited four peaks, the rest showed three distinct peaks, indicating endothermic and exothermic occurrences. As the temperature increased, a complex endothermic and exothermic behavior was visible with three distinct peaks. The first endothermic peaks $\left(119.48\right.$ and $\left.240.12{ }^{\circ} \mathrm{C}\right)$ were attributed to the loss of the residual moisture in the CG film due to heat absorption by the film, whereas the exothermic region around $311.74{ }^{\circ} \mathrm{C}$ was attributed to the breakdown and degradation of polysaccharide [47]. For the CG-CCSE 2, 148.40, 245.48 and $256.20^{\circ} \mathrm{C}$ were endothermic peaks, respectively. This finding also confirmed the strong thermal stability of CG-CCSE films compared with the control film, especially the first endothermic peak $\left(98.5^{\circ} \mathrm{C}\right)$ when the concentration was $1.2 \%$. Consequently, CCSE treatment could alter the structural arrangement between GA and CMC polymers. The treated films also showed a reduction in the temperature of the peak as the peak area increased. Likewise, the increase in DSC values of CG-CCSE films also corroborated the increase of the citric acid and polyphenols thermal stability. Wang et al. [48] reported that gelatin film mixture added with anthocyanins could yield tough gelatin and gelatin matrix between the anthocyanins and polymer molecules, which escalated the dissimilate temperatures and enhanced 
the thermal sturdiness of the films. The finding of DSC implied that the thermal stability of CCSE films in the CG matrix was concentration-dependent.

\subsection{Physical properties of CG-CCSE film}

\subsubsection{Thickness}

As presented in Table 2, the inclusion of CCSE did not affect the thickness of the CG films. However, it enhanced the soft elasticity and tensile strengths of the films. This might be due to the interactions between polyphenols and CG, causing a tighter binding of polyphenols and CG [9]. As CCSE concentration increased, nanoscale-quasi were produced following the continuous stirring with solid content addition and the interruption of the organized structure of the film matrix [49]. The polyphenol and CG interaction (including hydrophobic force and hydrogen bonding) increased and caused the tighter polyphenol-matrix binding, inducing the compartment of the film structure and enhanced surface smoothness. This phenomenon also supported the results of SEM and mechanical properties.

\subsubsection{Mechanical property of CG-CCSE film}

The mechanical property results for all the studied films are represented in Table 2 . In all of the checked films, the values of TS and EB were increased $(p<0.05)$. However, the CG control film showed low mechanical properties strength, and the mechanical properties of the CG control film were boosted by the inclusion of CCSE in the CG matrix. EB and TS results of CG control films were $37.24 \%$ and $33.01 \mathrm{MPa}$, while for CG-CCSE2, they were stated to be $70.03 \%$ and $63.23 \mathrm{MPa}$, respectively. The increased TS and EB in CG-CCSE films were due to abundant hydroxyl groups in citric acid and polyphenols that could form hydrogen bonds with the hydroxyl groups in CMC/GA, resulting in stronger interfacial adhesion between CG and CCSE [50]. Similar findings have previously been published $[4,48]$. On the other hand, intra-molecular forces, polymer composition, and the existence of crystallites beside the film network microstructure strongly rely on the mechanical property of a film [51]. It was apparent from the film SEM analytic results that an increase in CCSE concentration in the CG matrix led to the high homogeneity in the structure of CG control films, facilitating the strong interaction through hydrogen or ionic bonds within the CMC molecule and between GA and CCSE molecules [49]. Consequently, it could be assumed that CCSE inclusion promoted crystallinity and allowed the interchain interaction of CG, which resulted in EB and TS increase of the CCSE films.

\subsubsection{Moisture content, water solubility, and swelling degree}

The film's water resistance behavior is significantly induced by increase and decrease of swelling and water solubility, respectively [52]. The high solubility of CG in water makes it unfeasible to be used as a food packaging material. Hence, the incorporation of CCSE enhanced its water-resistant property. As presented in Table 3, a decline $(p<0.05)$ in water solubility and swelling was observed in CG-CCSE films. Hydroxyl groups (hydrophilic groups) in the CG molecule were integral for its intrinsic swelling behavior [53]. From the result, it is evident that the decrease in water solubility of CG-CCSE films was dose-dependent. This could be clarified due to the generation of powerful hydrogen bonds between the CG matrix and polyphenolic compounds. It was apparent that higher CCSE concentration decreased the water solubility of CG-CCSE films. Consequently, due to a decrease in water molecules linked with CG, the amount of water became less. These results supported the finding reported by Uranga et al. [54] and Rui et al. [55].

\subsubsection{WVP}

To determine the attitude of moisture permeability of the studied films, WVP analysis was carried out. The highest $\left(3.46 \times 10^{-11}\right.$ $\left.\mathrm{g} \cdot \mathrm{m}^{-1} \mathrm{~s}^{-1} \mathrm{~Pa}^{-1}\right)$ and lowest $\left(1.12 \times 10^{-11} \mathrm{~g} \cdot \mathrm{m}^{-1} \mathrm{~s}^{-1} \mathrm{~Pa}^{-1}\right)$ values were recorded in control and CG-CCSE $2 \%$ films (Table 3), respectively. The reduction could be linked to the less interactivity between the molecules of the water existing in the film following the effect of the cross-linking between glycerol, CG and CCSE, thereby promoting lower free water availability [56]. For food packaging films, low WVP values are very critical for preventing the transfer of moisture between food and the environment. Notably, the film thickness played a pivotal role in the water-barrier attribute. Films with optimal thickness possessed low WVP following the non-permeability of water molecules. Similar behavior was also documented as a result of the integration of the extract from black and blueberry into CG-based films [57].

\subsubsection{Color and opacity}


The color and opacity of food packaging material are integral indicators for consumer preference. All the variables were influenced $(p<0.05)$ by CCSE (Table 4$)$. The control films were extremely transparent while the color change was observed in the treated groups. A remarkable difference $(p<0.05)$ was recorded between all color indicator values $\left(L^{*}, a^{\star}\right.$, and $\left.b^{\star}\right)$. The color of the film became extra light amber in CG-CCSE 2 group (Fig. 1C). Film opacity also became higher $(p<0.05)$ by increasing CCSE concentration, making the films more opaque. Transparency in the film network is relevant to polymer alignment. The CG film was extremely transparent in comparison to the CG-CCSE film while the decrease in transparency was dose-dependent. The intermolecular bonding happened by CG and CCSE might be linked as the probable cause. The improvement in the characteristics of color and lowering the tendency of transparency in CG-CCSE films could be beneficial to protect food against color change, nutrient loss and off-flavor [58].

\subsection{CG-CCSE film bioactivities}

\subsubsection{Antioxidant activity}

The antioxidant potential is the primary feature of effective food packaging [59]. Thus, the scavenging activities on ABTS and DPPH free radicals of the films were investigated. The antioxidant activity of CG-CCSE films was improved $(p<0.05)$ by CCSE addition (Fig. 4A), as observed in the increase of antioxidant hydroxyl groups. The increase is associated with phenolic compounds in CCSE [32]. The antioxidant activity of the phenolic groups was contributed by the phenolic ring that can delocalize unpaired electrons and donate hydrogen from the hydroxyl groups [60]. As shown, the increase in the total phenolic contents was dose-dependent. Similarly, citric acid also acted as an antioxidant indirectly by chelating effect. Ounkaew et al. [61] reported that the DPPH scavenging activity of polyvinyl alcohol/starch film increased with increasing citric acid content. A similar result was also reported for an increase in antioxidant activity of biopolymer films incorporated with black soybean seed coat extracts of Pistacia terebinthus [38, 62].

\subsubsection{Antimicrobial activity}

The CG-CCSE films demonstrated an inhibitory effect $(p<0.05)$ on both Gram-negative $(E$. coli $)$ and Gram-positive $(S$. aureus and B. cereus) bacteria, and the inhibitory zones increased with increasing CCSE concentration in CG (Fig. 4B). The antimicrobial impact of CG films was attributed to high cellular permeability from bacterial cells and CG interaction. Snoussi et al. [63] asserted that the antimicrobial potential of an organic acid with phenolic compounds was linked to the physiological changes occurring in the bacterial membrane, ultimately resulting in cell death [64]. Moreover, citric acid present in CCSE might be involved in the reaction between thiosulfinates and thiol groups, resulting in the inactivation of thiolic enzymes present in Gram-negative bacteria and allyl-disulfide production, which further modified L-cysteine causing bacterial cell death [65]. Therefore, active packaging films should possess significant antimicrobial properties high enough to inhibit microbial growth and enhance the shelf life of foods [66].

\subsubsection{Biodegradation}

The biodegradable results of CG and CG-CCSE films are presented in Fig. 5. There was a significant $(p<0.05)$ weight loss in CGCCSE films as the days progressed. The CG-CCSE0.5 film showed the maximum loss in weight recorded about $44.77 \%$ after 3 weeks (Fig. 5A), whilst the lowest value (34.14\%) occurred in the control film (Fig. 5B). A similar biodegradation result was reported when root extract [46] and rosemary extracts [67] were incorporated into the cassava-starch film. The result showed that the CCSE incorporation enhanced Biodegradation following the generation of new polymeric materials, reducing adverse environmental impact by rapid regression.

\subsection{Potential application on sunflower oil packaging 3.5.1. Capability of films for oil resistance}

To ascertain the oil-resistant capability of the films, the oil absorption ratio (OAR) was assessed. The results showed no significant $(p>0.05)$ effect among the treated films. But between the CG- CCSE films and the CG control film, the OAR varied significantly $(p<$ 0.05). Films (CG-CCSE 1.2 and 2$)$ exhibited the lowest OAR $(0.13 \pm 0.087$ and $0.08 \pm 0.038)$, respectively, while the highest $(0.39 \pm$ 0.023 ) value was observed in CG control film (Table 5). The probable cause could be attributed to the existence of hydrophilic hydroxyl groups in the structure of CG and homogeneity in the structures without bubbles or pores of the films from CCSE 
inclusion, preventing the permeability of oil molecules out of the films. The low OAR value, therefore, demonstrated a more remarkable ability for oil resistance, which is an essential characteristic for oil products packaging material.

\subsubsection{Peroxide value (POV)}

POV is considered a parameter for producing lipid oxidation primary products (hydroperoxides) [68]. Although all POV values increased as days progressed, as presented in Table 5, the oxidation of CG-CCSE films was markedly $(p<0.05)$ reduced with open and CG controls observed with the highest values $(69.49 \pm 0.68$ and $20.15 \pm 0.31 \mathrm{mEq} / \mathrm{kg}$, respectively), while the lowest value $(9.79 \pm 0.28 \mathrm{mEq} / \mathrm{kg})$ was recorded in CG-CCSE 2 . Simultaneously, the color changes and oxidation of oils were detected by naked eyes when kept at $50{ }^{\circ} \mathrm{C}$ for 28 days (as shown graphically in Fig. 6). The higher POV of sunflower oil for the CG film might be a result of the discontinuities in the matrix of the CG film (Fig. 1A), which would permit accelerated oil oxidation. The high level of unsaturated fatty acids in the oil and direct exposure to external oxygen could be probable causes. The compacted structure of the bio-composite film showed an integral part in reducing oxidation by making oxygen impermeable [9]. The slow release of the citric acid from the CG-CCSE was probably proficient to improve the balance of citric acid and retard the oxidation process of the sunflower oil during preservation [61]. Besides, the antioxidant potency of the film following the availability of citric acid and polyphenols also induced the retardation of the oxidative processes. Therefore, it can be concluded that CG-based CCSE films, possessing good bioactive properties, can be used for active packaging applications to prevent oxidation and deterioration of food.

\section{Conclusion}

C. camphora seeds, regarded as food scraps, possess rich bioactive compounds such as citric acid 4-hydroxybenzoic acid, and other phenolic compounds, which can be explored as a potential packaging alternative. In this study, the effect of CCSE as a bioactive agent was evaluated after inclusion into CG-based food packaging films. The incorporation enhanced the CG films physical properties, including thickness, water solubility, and moisture content and swelling degree. Also, water vapor had been reduced, indicating the perfect barrier potential of CG-CCSE films. Moreover, the total color features were improved from transparent to opaque, including good antioxidant and inhibitory activities against the tested bacterial types. Thus, CG-based CCSE films should be employed in the food industry as eco-friendly films in food packaging.

\section{Abbreviations}

CCSE, Cinnamomum camphora seeds extract; CG, carboxymethyl chitosan with gum Arabic; CG-CCSE, carboxymethyl chitosangum Arabic with $C$. camphora seeds extract; CMC, carboxymethyl chitosan; EB, elongation at break; GA, gum Arabic; LC-ESI-QTOFMS, liquid chromatography coupled with electrospray-ionisation triple quadrupole time-of-flight mass spectrometry; POV, peroxide value; TS, tensile strength; WVP, water vapor permeability

\section{Declarations}

\section{Author statements}

The authors have declared that there is no conflict of interest.

Fawze Alnadari: Conceptualization, Software, Writing original draft. Anthony Pius Bassey: Methodology, Investigation. Mohamed Abdin: Methodology, Data Curation. Mohamed Abdelbaset Salama: Methodology, Writing-original draft. Mustapha Muhammad Nasiru: Writing-original draft, Data curation. Zhuqing Dai: Investigation. Yuhang Hu: Investigation. Xiaoxiong Zeng: Conceptualization, Supervision, Funding, Project administration.

\section{Acknowledgments}

This work was supported by a project funded by the Priority Academic Program Development of Jiangsu Higher Education Institutions.

\section{References}


1. Abdin M, El-Beltagy A, El-sayed M, Naeem MA (2021a) Production and Characterization of Sodium Alginate/Gum Arabic Based Films Enriched with Syzygium cumini Seeds Extracts for Food Application.J Polym Environ,1-12

2. Abdin M, Salama MA, Gawad R, Fathi MA, Alnadari F (2021b) Two-Steps of Gelation System Enhanced the Stability of Syzygium cumini Anthocyanins by Encapsulation with Sodium Alginate, Maltodextrin, Chitosan and Gum Arabic.J Polym Environ, $1-14$

3. Adilah AN, Jamilah B, Noranizan M, Hanani ZN (2018a) Utilization of mango peel extracts on the biodegradable films for active packaging. Food Packag Shelf Life 16:1-7

4. Adilah ZM, Jamilah B, Hanani ZN (2018b) Functional and antioxidant properties of protein-based films incorporated with mango kernel extract for active packaging. Food Hydrocoll 74:207-218

5. Akhtar HMS, Riaz A, Hamed YS, Abdin M, Chen G, Wan P, Zeng X (2018) Production and characterization of CMC-based antioxidant and antimicrobial films enriched with chickpea hull polysaccharides. Int J Biol Macromol 118:469-477

6. Ali A, Chen Y, Liu H, Yu L, Baloch Z, Khalid S, Zhu J, Chen L (2019) Starch-based antimicrobial films functionalized by pomegranate peel. Int J Biol Macromol 129:1120-1126

7. Ali A, Maqbool M, Ramachandran S, Alderson PG (2010) Gum arabic as a novel edible coating for enhancing shelf-life and improving postharvest quality of tomato (Solanum lycopersicum L.) fruit. Postharvest Biolo Techn 58(1):42-47

8. Arfat YA, Ahmed J, Hiremath N, Auras R, Joseph A (2017) Thermo-mechanical, rheological, structural and antimicrobial properties of bionanocomposite films based on fish skin gelatin and silver-copper nanoparticles. Food Hydrocoll 62:191-202

9. Bai R, Zhang X, Yong H, Wang X, Liu Y, Liu J (2019) Development and characterization of antioxidant active packaging and intelligent Al3+-sensing films based on carboxymethyl chitosan and quercetin. Int J Biol Macromol 126:1074-1084

10. Bifani V, Ramírez C, Ihl M, Rubilar M, García A, Zaritzky N (2007) Effects of murta (Ugni molinae Turcz) extract on gas and water vapor permeability of carboxymethylcellulose-based edible films. LWT Food Sci Technol 40(8):1473-1481

11. Cazón P, Velazquez G, Ramírez JA, Vázquez M (2017) Polysaccharide-based films and coatings for food packaging: A review. Food Hydrocoll 68:136-148

12. Cheng S-Y, Wang B-J, Weng Y-M (2015) Antioxidant and antimicrobial edible zein/chitosan composite films fabricated by incorporation of phenolic compounds and dicarboxylic acids. LWT Food Sci Technol 63(1):115-121

13. Ciannamea EM, Stefani PM, Ruseckaite RA (2016) Properties and antioxidant activity of soy protein concentrate films incorporated with red grape extract processed by casting and compression molding. LWT Food Sci Technol 74:353-362

14. Cox KD, Covernton GA, Davies HL, Dower JF, Juanes F, Dudas SE (2019) Human consumption of microplastics. Environ Sci Technol 53(12):7068-7074

15. Dou L, Li B, Zhang K, Chu X, Hou H (2018) Physical properties and antioxidant activity of gelatin-sodium alginate edible films with tea polyphenols. Int J Biol Macromol 118:1377-1383

16. Fu J, Zeng C, Zeng Z, Wang B, Gong D (2016) Cinnamomum camphora seed kernel oil ameliorates oxidative stress and inflammation in diet-induced obese rats. J Food Sci 81(5):H1295-H1300

17. General Administration of Quality Supervision Inspection and Quarantine of the People's Republic of China (2016)National standards of the People's Republic of China

18. Gómez-Estaca J, López-de-Dicastillo C, Hernández-Muñoz P, Catalá R, Gavara R (2014) Advances in antioxidant active food packaging. Trends Food Sci Techno 35(1):42-51

19. Guo S, Geng Z, Zhang W, Liang J, Wang C, Deng Z, Du S (2016) The chemical composition of essential oils from Cinnamomum camphora and their insecticidal activity against the stored product pests. Intern J Molecular Sci 17(11):1836

20. Hafsa J, ali Smach M, Khedher MRB, Charfeddine B, Limem K, Majdoub H, Rouatbi S (2016) Physical, antioxidant and antimicrobial properties of chitosan films containing Eucalyptus globulus essential oil. LWT Food Sci Technol 68:356-364

21. Hassan B, Chatha SAS, Hussain Al, Zia KM, Akhtar N (2018) Recent advances on polysaccharides, lipids and protein based edible films and coatings: A review. Int J Biol Macromol 109:1095-1107

22. Hosseini SF, Rezaei M, Zandi M, Farahmandghavi F (2016) Development of bioactive fish gelatin/chitosan nanoparticles composite films with antimicrobial properties. Food Chem 194:1266-1274 
23. Huang G-Q, Du Y-L, Xiao J-X, Wang G-Y (2017) Effect of coacervation conditions on the viscoelastic properties of N, Ocarboxymethyl chitosan-gum Arabic coacervates. Food Chem 228:236-242

24. Hussain G, Rahman A, Hussain T, Uddin S, Ali T (2015) Citric and lactic acid effects on the growth Inhibition of E. coli and S. typhymurium on beef during storage. Sarhad J Agric 31(3):183-190

25. Islam E, Islam R, Rahman AA, Alam AK, Khondkar P, Rashid M, Parvin S (2013) Estimation of total phenol and in vitro antioxidant activity of Albizia procera leaves. BMC Res notes 6(1):1-7

26. Kang S, Xiao Y, Guo X, Huang A, Xu H (2021) Development of gum arabic-based nanocomposite films reinforced with cellulose nanocrystals for strawberry preservation. Food Chem 350:129199

27. Kaya M, Khadem S, Cakmak YS, Mujtaba M, Ilk S, Akyuz L, Salaberria AM, Labidi J, Abdulqadir AH, Deligöz E (2018) Antioxidative and antimicrobial edible chitosan films blended with stem, leaf and seed extracts of Pistacia terebinthus for active food packaging. RSC Adv 8(8):3941-3950

28. Khalid S, Yu L, Feng M, Meng L, Bai Y, Ali A, Liu H, Chen L (2018) Development and characterization of biodegradable antimicrobial packaging films based on polycaprolactone, starch and pomegranate rind hybrids. Food Packag Shelf Life 18:71-79

29. Liu C-M, Perng M-H, Chen C-Y (2018) Antioxidant activities of crude extracts from peel and seed of Cinnamomum camphora. Biomedical Research (0970-938X), 29(13)

30. Liu J, Liu S, Chen Y, Zhang L, Kan J, Jin C (2017a) Physical, mechanical and antioxidant properties of chitosan films grafted with different hydroxybenzoic acids. Food Hydrocoll 71:176-186

31. Liu J, Meng C-g, Liu S, Kan J, Jin C-h (2017b) Preparation and characterization of protocatechuic acid grafted chitosan films with antioxidant activity. Food Hydrocoll 63:457-466

32. Martins JT, Cerqueira MA, Vicente AA (2012) Influence of a-tocopherol on physicochemical properties of chitosan-based films. Food Hydrocoll 27(1):220-227

33. Medina-Jaramillo C, Ochoa-Yepes O, Bernal C, Famá L (2017) Active and smart biodegradable packaging based on starch and natural extracts. Carbohydr Polym 176:187-194

34. Muppalla SR, Chawla S (2018) Effect of Gum Arabic-polyvinyl alcohol films containing seed cover extract of Zanthoxylum rhetsa on shelf life of refrigerated ground chicken meat.J Food Safety, 38(4), e12460

35. Otoni CG, Avena-Bustillos RJ, Azeredo HM, Lorevice MV, Moura MR, Mattoso LH, McHugh TH (2017) Recent advances on edible films based on fruits and vegetables-a review. Compr R Food Sci Food Safety 16(5):1151-1169

36. Ounkaew A, Kasemsiri P, Kamwilaisak K, Saengprachatanarug K, Mongkolthanaruk W, Souvanh M, Pongsa U, Chindaprasirt P (2018) Polyvinyl alcohol (PVA)/starch bioactive packaging film enriched with antioxidants from spent coffee ground and citric acid. J Polym Environ 26(9):3762-3772

37. Palacios I, Lozano M, Moro C, D’arrigo M, Rostagno M, Martínez J, García-Lafuente A, Guillamón E, Villares A (2011) Antioxidant properties of phenolic compounds occurring in edible mushrooms. Food Chem 128(3):674-678

38. Pastor C, Sánchez-González L, Chiralt A, Cháfer M, González-Martínez C (2013) Physical and antioxidant properties of chitosan and methylcellulose based films containing resveratrol. Food Hydrocoll 30(1):272-280

39. Piñeros-Hernandez D, Medina-Jaramillo C, López-Córdoba A, Goyanes S (2017) Edible cassava starch films carrying rosemary antioxidant extracts for potential use as active food packaging. Food Hydrocoll 63:488-495

40. Priyadarshi R, Kumar B, Deeba F, Kulshreshtha A, Negi YS (2018) Chitosan films incorporated with Apricot (Prunus armeniaca) kernel essential oil as active food packaging material. Food Hydrocoll 85:158-166

41. Qin Y, Liu Y, Yong H, Liu J, Zhang X, Liu J (2019) Preparation and characterization of active and intelligent packaging films based on cassava starch and anthocyanins from Lycium ruthenicum Murr. Int J Biol Macromol 134:80-90

42. Riaz A, Lagnika C, Luo H, Dai Z, Nie M, Hashim MM, Liu C, Song J, Li D (2020a) Chitosan-based biodegradable active food packaging film containing Chinese chive (Allium tuberosum) root extract for food application. Int J Biol Macromol 150:595604

43. Riaz A, Lagnika C, Luo H, Nie M, Dai Z, Liu C, Abdin M, Hashim MM, Li D, Song J (2020b) Effect of Chinese chives (Allium tuberosum) addition to carboxymethyl cellulose based food packaging films. Carbohydr Polym 235:115944

Page $13 / 19$ 
44. Ribeiro AM, Estevinho BN, Rocha F (2020) Edible Films Prepared with Different Biopolymers, Containing Polyphenols Extracted from Elderberry (Sambucus Nigra L.), to Protect Food Products and to Improve Food Functionality. Food Bioprocess Techn 13(10):1742-1754

45. Rui L, Xie M, Hu B, Zhou L, Yin D, Zeng X (2017) A comparative study on chitosan/gelatin composite films with conjugated or incorporated gallic acid. Carbohydr Polym 173:473-481

46. Salama MA, El Harkaoui S, Nounah I, Sakr H, Abdin M, Owon M, Osman M, Ibrahim A, Charrouf Z, Matthäus B (2020) Oxidative stability of Opuntia ficus-indica seeds oil blending with Moringa oleifera seeds oil囚. OCL 27:53

47. Shariatinia Z (2018) Carboxymethyl chitosan: Properties and biomedical applications. Int J Biol Macromol 120:1406-1419

48. Siripatrawan U, Harte BR (2010) Physical properties and antioxidant activity of an active film from chitosan incorporated with green tea extract. Food Hydrocoll 24(8):770-775

49. Snoussi M, Trabelsi N, Dehmeni A, Benzekri R, Bouslama L, Hajlaoui B, Al-sieni A, Papetti A (2016) Phytochemical analysis, antimicrobial and antioxidant activities of Allium roseum var. odoratissimum (Desf.) Coss extracts. Ind Crops Prod 89:533542

50. Strawski M, Granicka LH, Szklarczyk M (2017) Redox properties of polyelectrolyte multilayer modified electrodes: a significant effect of the interactions between the polyelectrolyte layers in the films. Electrochim Acta 226:121-131

51. Suriyatem R, Auras RA, Rachtanapun C, Rachtanapun P (2018) Biodegradable rice starch/carboxymethyl chitosan films with added propolis extract for potential use as active food packaging. Polymers 10(9):954

52. Tahsiri Z, Mirzaei H, Hosseini SMH, Khalesi M (2019) Gum arabic improves the mechanical properties of wild almond protein film. Carbohydr Polym 222:114994

53. Tan Z, Yi Y, Wang H, Zhou W, Yang Y, Wang C (2016) Physical and degradable properties of mulching films prepared from natural fibers and biodegradable polymers. Appl Sci 6(5):147

54. Tripathi N, Katiyar V (2016) PLA/functionalized-gum arabic based bionanocomposite films for high gas barrier applications.J Appl Polym Sci, 133(21)

55. Uranga J, Puertas A, Etxabide A, Dueñas M, Guerrero P, De La Caba K (2019) Citric acid-incorporated fish gelatin/chitosan composite films. Food Hydrocoll 86:95-103

56. Wang L, Guo H, Wang J, Jiang G, Du F, Liu X (2019a) Effects of Herba Lophatheri extract on the physicochemical properties and biological activities of the chitosan film. Int J Biol Macromol 133:51-57

57. Wang S, Xia P, Wang S, Liang J, Sun Y, Yue P, Gao X (2019b) Packaging films formulated with gelatin and anthocyanins nanocomplexes: physical properties, antioxidant activity and its application for olive oil protection. Food Hydrocoll 96:617624

58. Wang X, Yong H, Gao L, Li L, Jin M, Liu J (2019c) Preparation and characterization of antioxidant and pH-sensitive films based on chitosan and black soybean seed coat extract. Food Hydrocoll, 89(APR.), 56-66

59. Wu J, Zhong F, Li Y, Shoemaker C, Xia W (2013) Preparation and characterization of pullulan-chitosan and pullulancarboxymethyl chitosan blended films. Food Hydrocoll 30(1):82-91

60. Wu Y, Luo X, Li W, Song R, Li J, Li Y, Li B, Liu S (2016) Green and biodegradable composite films with novel antimicrobial performance based on cellulose. Food Chem 197:250-256

61. Xu C, Feng X, Huang M, Yang Y, Shen X, Tang X (2019a) Cinnamon and clove essential oils to improve physical, thermal and antimicrobial properties of chitosan-gum arabic polyelectrolyte complexed films. Carbohydr Polym 217:116-125

62. Xu T, Gao C, Feng X, Huang M, Yang Y, Shen X, Tang X (2019b) Cinnamon and clove essential oils to improve physical, thermal and antimicrobial properties of chitosan-gum arabic polyelectrolyte complexed films. Carbohydr Polym 217:116-125

63. Xu Y, Zhu X, Ma X, Xiong H, Zeng Z, Peng H, Hu J (2018) Enzymatic production of trans-free shortening from coix seed oil, fully hydrogenated palm oil and Cinnamomum camphora seed oil. Food bioscience 22:1-8

64. Yan X, Liang S, Peng T, Zhang G, Zeng Z, Yu P, Gong D, Deng S (2020) Influence of phenolic compounds on physicochemical and functional properties of protein isolate from Cinnamomum camphora seed kernel. Food Hydrocoll 102:105612

65. Yong H, Wang X, Bai R, Miao Z, Zhang X, Liu J (2019) Development of antioxidant and intelligent pH-sensing packaging films by incorporating purple-fleshed sweet potato extract into chitosan matrix. Food Hydrocoll 90:216-224

Page $14 / 19$ 
66. Zhang G, Yan X, Wu S, Ma M, Yu P, Gong D, Deng S, Zeng Z (2020) Ethanol extracts from Cinnamomum camphora seed kernel: Potential bioactivities as affected by alkaline hydrolysis and simulated gastrointestinal digestion. Food Res Int 137:109363

67. Zhang P, Zhao Y, Shi Q (2016) Characterization of a novel edible film based on gum ghatti: Effect of plasticizer type and concentration. Carbohydr Polym 153:345-355

68. Zimet P, Mombrú ÁW, Mombrú D, Castro A, Villanueva JP, Pardo H, Rufo C (2019) Physico-chemical and antilisterial properties of nisin-incorporated chitosan/carboxymethyl chitosan films. Carbohydr Polym 219:334-343

\section{Tables}

Table 1

Identification and quantification of compounds from CCSE extract by using LC-ESI-QTOF-MS.

\begin{tabular}{|c|c|c|c|c|c|c|c|}
\hline No & $\begin{array}{l}\text { Name of } \\
\text { compound }\end{array}$ & $\begin{array}{l}\text { Retention time } \\
\text { (tr/min) }\end{array}$ & $\begin{array}{l}{[\mathrm{M}-\mathrm{H}]-} \\
\mathrm{m} / \mathrm{z}\end{array}$ & $\begin{array}{l}{[\mathrm{M}+\mathrm{H}]+} \\
\mathrm{m} / \mathrm{z}\end{array}$ & Calibration equation & $\begin{array}{l}\text { Regression coefficient } \\
\left(\mathrm{R}^{2}\right)\end{array}$ & $\begin{array}{l}\text { Content } \\
(\mathrm{mg} / \mathrm{g} \\
\mathrm{dw})\end{array}$ \\
\hline 1 & $\begin{array}{l}\text { Procatechuic } \\
\text { acid }\end{array}$ & 2.31 & 153.0188 & 155.0345 & $g=16055 x+15230$ & 0.998 & -35 \\
\hline 2 & Catechin & 3.86 & 289.0712 & 291.0869 & $g=34984 x+78939$ & 0.9932 & -86.52 \\
\hline 3 & Caffeic acid & 4.45 & 179.0344 & 181.0501 & $g=31698 x+30606$ & 0.9907 & -34.56 \\
\hline 4 & Epicatechin & 5.24 & 289.0712 & 291.0869 & $g=34400 x+40232$ & 0.9907 & -42.83 \\
\hline 5 & Ferulic acid & 7.13 & 193.05 & 195.0657 & $g=14744 x+9076.8$ & 0.9923 & -18.85 \\
\hline 6 & $\begin{array}{l}\text { Ferulic acid } \\
\text { isomer }\end{array}$ & 3.41 & 193.05 & 195.0657 & $g=14744 x+9076.8$ & 0.9945 & -3.33 \\
\hline 7 & Rutin & 7.67 & 609.1456 & 611.1612 & $g=41507 x+32683$ & 0.9969 & -20.88 \\
\hline 8 & Salicyclic acid & 8.93 & 137.0239 & 139.0395 & $g=28337 x+15500$ & 0.9991 & -21.03 \\
\hline 9 & Citric acid & 0.99 & 191.0192 & 193.0348 & $g=5970.9 x-545.05$ & 0.994 & 1062.55 \\
\hline 10 & $\begin{array}{l}\text { 4- } \\
\text { hydroxybenzoic } \\
\text { acid }\end{array}$ & 3.52 & 137.0239 & 139.0395 & $g=8136.4 x+6108.1$ & 0.997 & 19.02 \\
\hline 11 & Procyanidin B3 & 3.48 & 577.1346 & 579.1503 & $g=27220 x+28992$ & 0.9956 & -23.53 \\
\hline 12 & $\begin{array}{l}\text { P-coumaric } \\
\text { acid }\end{array}$ & 6.16 & 163.0395 & 165.054 & $g=21382 x+20278$ & 0.9942 & 6.62 \\
\hline 13 & Phlorizin & 10.56 & 435.1291 & 437.1448 & $g=27330 x+25878$ & 0.9993 & -29.72 \\
\hline 14 & $\begin{array}{l}\text { Chlorogenic } \\
\text { acid }\end{array}$ & 3.85 & 353.0893 & 355.1029 & $g=31698 x+30606$ & 0.9927 & -37.48 \\
\hline 15 & Sinapic acid & 4.04 & 223.0565 & 225.0722 & - & - & - \\
\hline 16 & $\begin{array}{l}\text { Feruloylquinic } \\
\text { acid }\end{array}$ & 7.7 & 337.0922 & 339.1079 & - & - & - \\
\hline 17 & Morin & 9.06 & 301.0348 & 303.0503 & - & - & - \\
\hline
\end{tabular}

\section{Table 2}

Thickness and mechanical property of CG-based CCSE films. 


\begin{tabular}{llll} 
Film sample & $\begin{array}{l}\text { Thickness } \\
(\mathrm{mm})\end{array}$ & $\begin{array}{l}\text { Tensile strength } \\
(\mathrm{MPa})\end{array}$ & $\begin{array}{l}\text { Elongation Break } \\
(\%)\end{array}$ \\
\hline CG & $0.025 \pm 0.0029^{\mathrm{a}}$ & $33.01 \pm 0.48^{\mathrm{d}}$ & $37.24 \pm 0.92^{\mathrm{d}}$ \\
\hline CG-CCSE 0.5 & $0.02 \pm 0.003^{\mathrm{a}}$ & $37.54 \pm 1.10^{\mathrm{c}}$ & $44.06 \pm 0.60^{\mathrm{c}}$ \\
\hline CG-CCSE 1.2 & $0.026 \pm 0.0028^{\mathrm{a}}$ & $54.50 \pm 0.20^{\mathrm{b}}$ & $57.38 \pm 1.94^{\mathrm{b}}$ \\
\hline CG-CCSE 2 & $0.024 \pm 0.00067^{\mathrm{a}}$ & $63.23 \pm 0.91^{\mathrm{a}}$ & $70.03 \pm 0.69^{\mathrm{a}}$
\end{tabular}

Values are expressed as mean \pm standard deviation. Different letters in the same column indicate significant differences $(p<$ 0.05).

\section{Table 3}

Physical properties of CG-based CCSE films.

\begin{tabular}{lllll} 
Film sample & $\begin{array}{l}\text { Swelling degree } \\
(\%)\end{array}$ & $\begin{array}{l}\text { Solubility } \\
(\%)\end{array}$ & $\begin{array}{l}\text { Moisture content } \\
(\%)\end{array}$ & $\begin{array}{l}\text { WVP } \\
\left(\times 10^{-11} \mathrm{~g}^{-1} \mathrm{~s}^{-1} \mathrm{~Pa}^{-1}\right)\end{array}$ \\
\hline CG & $54.21 \pm 6.21^{\mathrm{b}}$ & $32.05 \pm 0.45^{\mathrm{d}}$ & $16.92 \pm 0.33^{\mathrm{d}}$ & $3.46 \pm 0.01^{\mathrm{a}}$ \\
\hline CG-CCSE 0.5 & $47.66 \pm 5.41^{\mathrm{b}}$ & $25.54 \pm 0.51^{\mathrm{c}}$ & $14.46 \pm 0.17^{\mathrm{c}}$ & $2.37 \pm 0.01^{\mathrm{b}}$ \\
\hline CG-CCSE 1.2 & $42.53 \pm 1.88^{\mathrm{a}} \mathrm{b}$ & $17.69 \pm 0.62^{\mathrm{b}}$ & $12.70 \pm 0.50^{\mathrm{b}}$ & $1.67 \pm 0.03^{\mathrm{c}}$ \\
\hline CG-CCSE 2 & $31.70 \pm 1.25^{\mathrm{a}}$ & $14.02 \pm 0.38^{\mathrm{a}}$ & $10.97 \pm 0.30^{\mathrm{a}}$ & $1.12 \pm 0.02^{\mathrm{d}}$
\end{tabular}

Values are expressed as mean standard deviation. Different letters in the same column indicate significant differences $(p \quad 0.05)$.

\section{Table 4}

Color and opacity of CG-base films with different concentration of CCSE

\begin{tabular}{|c|c|c|c|c|c|c|c|}
\hline $\begin{array}{l}\text { Film } \\
\text { sample }\end{array}$ & $L^{*}$ & $a^{*}$ & $b^{\star}$ & $\Delta \mathrm{E}$ & YI & WI & $\begin{array}{l}\text { Opacity } \\
(\mathrm{mm}-1)\end{array}$ \\
\hline CG & $\begin{array}{l}84.98 \pm \\
0.43^{c}\end{array}$ & $\begin{array}{l}-1.15 \pm \\
0.03^{a}\end{array}$ & $3.40 \pm 0.49^{a}$ & $9.19 \pm 0.43^{\mathrm{a}}$ & $5.72 \pm 0.06^{a}$ & $\begin{array}{l}84.56 \pm \\
0.41^{d}\end{array}$ & $1.16 \pm 0.07^{a}$ \\
\hline $\begin{array}{l}\text { CG-CCSE } \\
0.5\end{array}$ & $\begin{array}{l}71.45 \pm \\
1.05^{\mathrm{b}}\end{array}$ & $4.22 \pm 0.44^{b}$ & $\begin{array}{l}12.04 \pm \\
0.32^{b}\end{array}$ & $\begin{array}{l}24.37 \pm \\
1.16^{\mathrm{b}}\end{array}$ & $\begin{array}{l}24.09 \pm \\
0.96^{\mathrm{b}}\end{array}$ & $\begin{array}{l}68.72 \pm \\
1.13^{c}\end{array}$ & $\begin{array}{l}10.43 \pm \\
0.42^{b}\end{array}$ \\
\hline $\begin{array}{l}\text { CG-CCSE } \\
1.2\end{array}$ & $\begin{array}{l}66.84 \pm \\
0.89^{a}\end{array}$ & $5.35 \pm 0.24^{c}$ & $22.73 \pm 0.14^{c}$ & $\begin{array}{l}33.38 \pm \\
0.55^{c}\end{array}$ & $\begin{array}{l}48.60 \pm \\
0.38^{c}\end{array}$ & $\begin{array}{l}59.43 \pm \\
0.55^{\mathrm{b}}\end{array}$ & $\begin{array}{l}13.76 \pm \\
0.23^{c}\end{array}$ \\
\hline CG-CCSE 2 & $\begin{array}{l}65.63 \pm \\
0.19^{a}\end{array}$ & $6.22 \pm 0.28^{c}$ & $\begin{array}{l}25.10 \pm \\
0.02^{d}\end{array}$ & $\begin{array}{l}35.84 \pm \\
0.20^{d}\end{array}$ & $\begin{array}{l}54.64 \pm \\
0.16^{d}\end{array}$ & $\begin{array}{l}56.98 \pm \\
0.19^{a}\end{array}$ & $\begin{array}{l}21.59 \pm \\
1.24^{\mathrm{d}}\end{array}$ \\
\hline
\end{tabular}

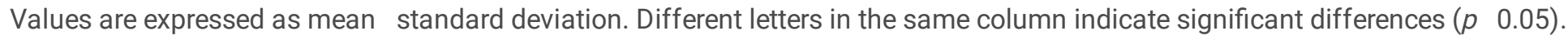

\section{Table 5}

Oil absorption ratio (OAR \%) of CG-CCSE films and POV $(\mathrm{mEq} / \mathrm{kg})$ of sunflower oil stored in CG-CCSE films 


\begin{tabular}{lllllll} 
Film sample & OAR & POV & & & \\
\cline { 3 - 6 } & & Day 1 & Day 7 & Day 14 & Day 21 & Day 28 \\
\hline Open control & - & $2.83 \pm 0.20^{\mathrm{a}}$ & $8.01 \pm 0.20^{\mathrm{d}}$ & $22.00 \pm 0.54^{\mathrm{c}}$ & $41.03 \pm 0.47^{\mathrm{d}}$ & $69.49 \pm 0.68^{\mathrm{d}}$ \\
\hline CG & $0.39 \pm 0.023^{\mathrm{b}}$ & $2.64 \pm 0.22^{\mathrm{a}}$ & $6.67 \pm 0.24^{\mathrm{c}}$ & $10.48 \pm 0.48^{\mathrm{b}}$ & $15.64 \pm 0.68^{\mathrm{c}}$ & $20.15 \pm 0.31^{\mathrm{c}}$ \\
\hline CG-CCSE 0.5 & $0.19 \pm 0.066^{\mathrm{a}}$ & $2.63 \pm 0.24^{\mathrm{a}}$ & $6.19 \pm 0.17^{\mathrm{c}}$ & $9.76 \pm 0.24^{\mathrm{b}}$ & $14.36 \pm 0.51^{\mathrm{c}}$ & $17.36 \pm 0.46^{\mathrm{b}, \mathrm{c}}$ \\
\hline CG-CCSE 1.2 & $0.13 \pm 0.087^{\mathrm{a}}$ & $2.66 \pm 0.26^{\mathrm{a}}$ & $4.93 \pm 0.00^{\mathrm{b}}$ & $7.78 \pm 0.27^{\mathrm{a}}$ & $10.46 \pm 0.26^{\mathrm{b}}$ & $15.13 \pm 2.16^{\mathrm{b}}$ \\
\hline CG-CCSE 2 & $0.08 \pm 0.038^{\mathrm{a}}$ & $2.63 \pm 0.19^{\mathrm{a}}$ & $4.33 \pm 0.24^{\mathrm{a}}$ & $6.76 \pm 0.56^{\mathrm{a}}$ & $7.69 \pm 0.00^{\mathrm{a}}$ & $9.79 \pm 0.28^{\mathrm{a}}$
\end{tabular}

Values are expressed as mean standard deviation. Different letters in the same column indicate significant differences $\left(\begin{array}{ll}p & 0.05\end{array}\right)$.

\section{Figures}

(A)

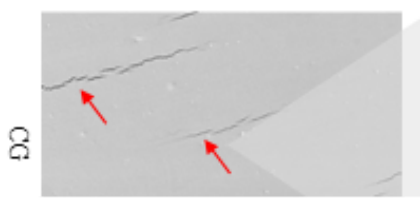

(B)

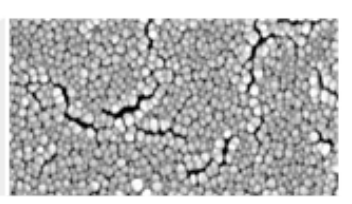

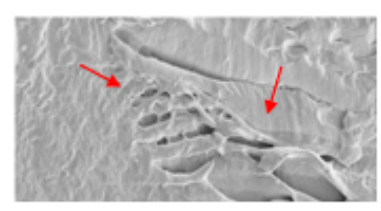

(C)

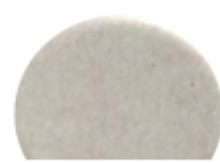

\section{Figure 1}

(A) Surface-sectioned SEM, (B) Cross-sectioned SEM, (C) Graphics of CG-CCSE films. 
(A)

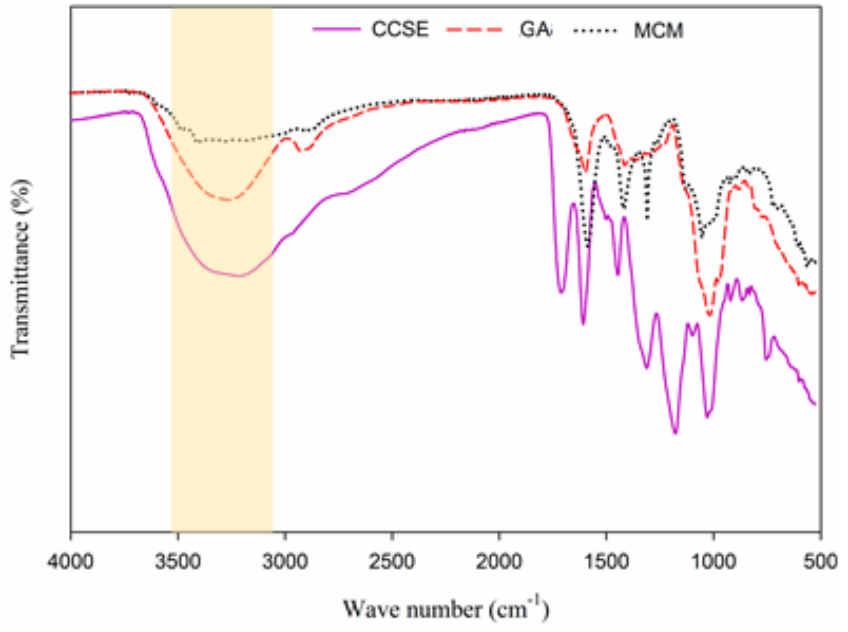

(B)

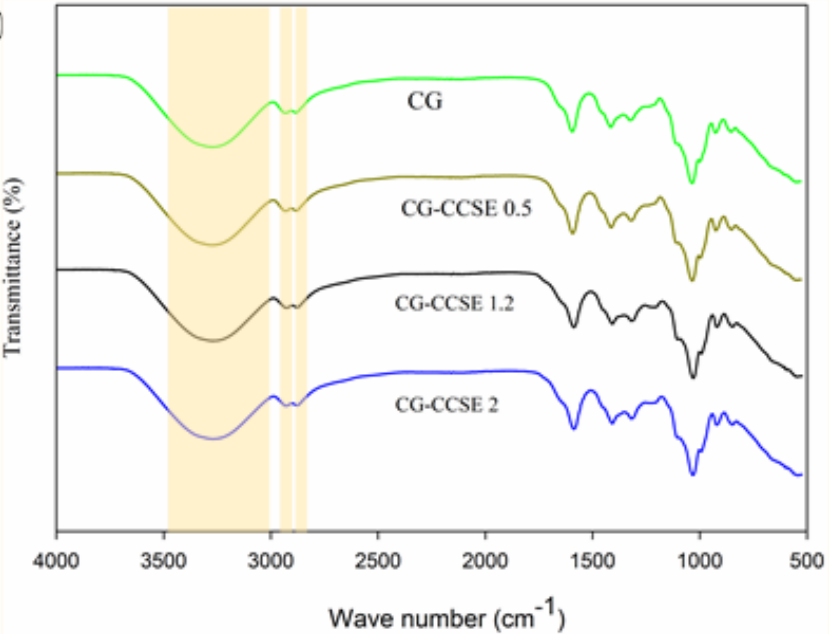

Figure 2

(A) FTIR spectra of CCSE, GA and CMC, (B) FTIR spectra of CG films containing CCSE at different concentrations.

(A)

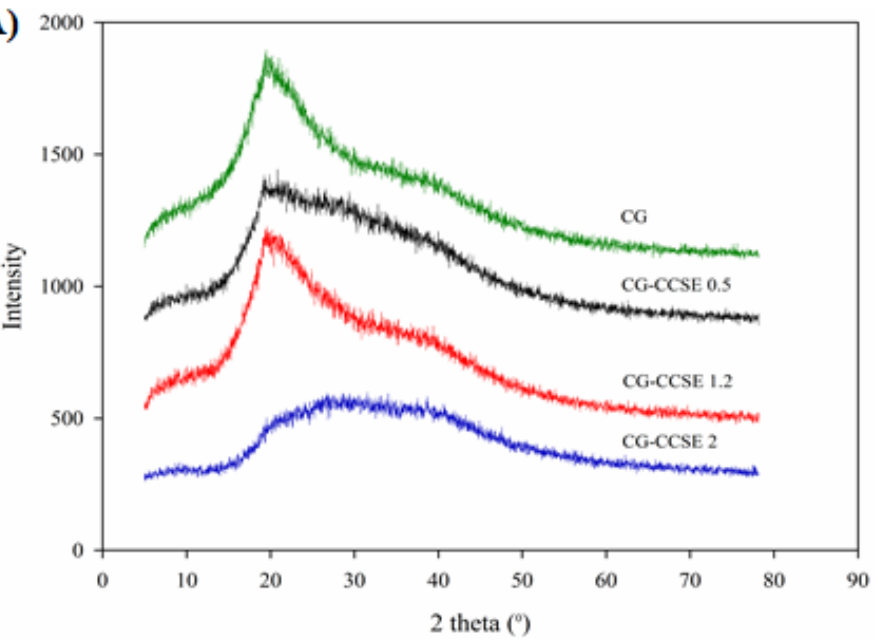

(B)

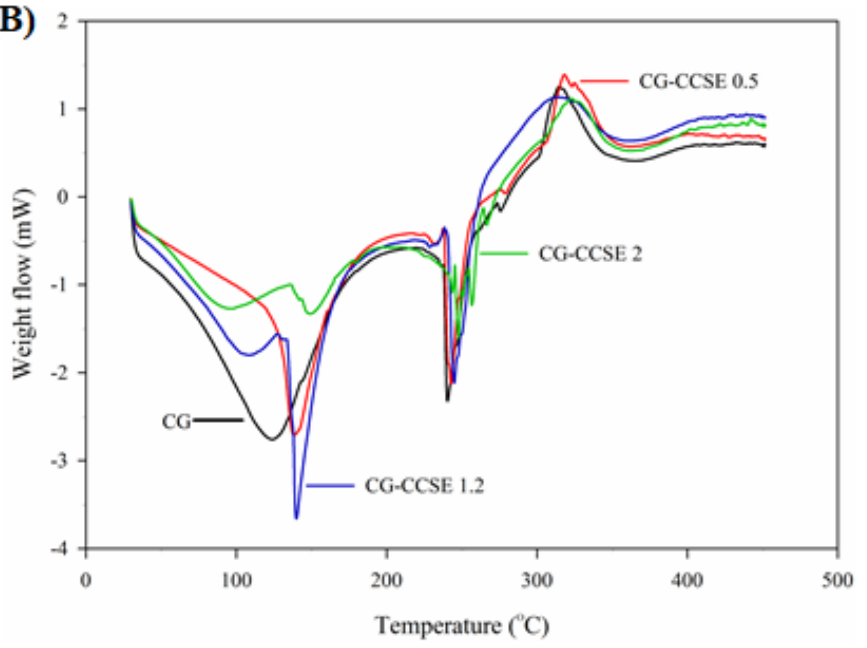

Figure 3

(A) X-RD pattern of CG-CCSE films, (B) DSC thermograms CG-CCSE films.

(A)

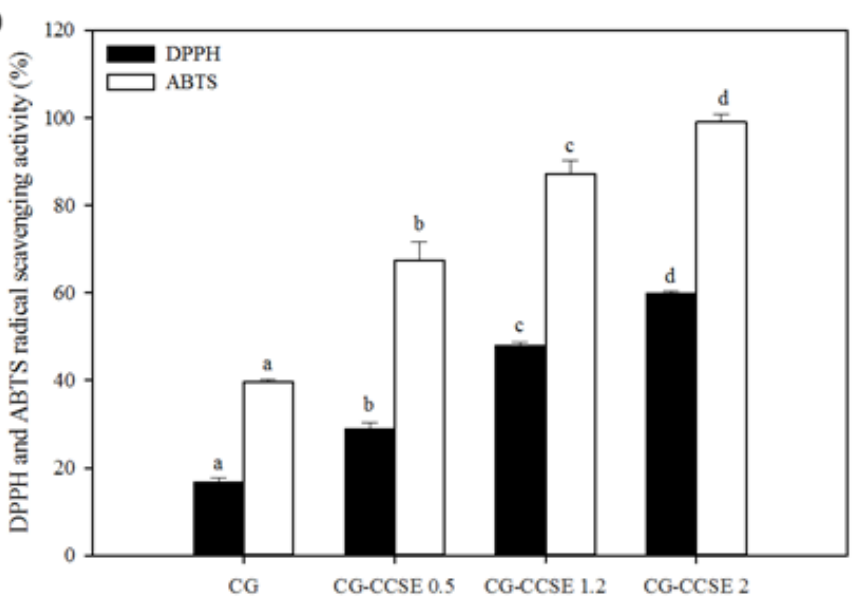

(B)

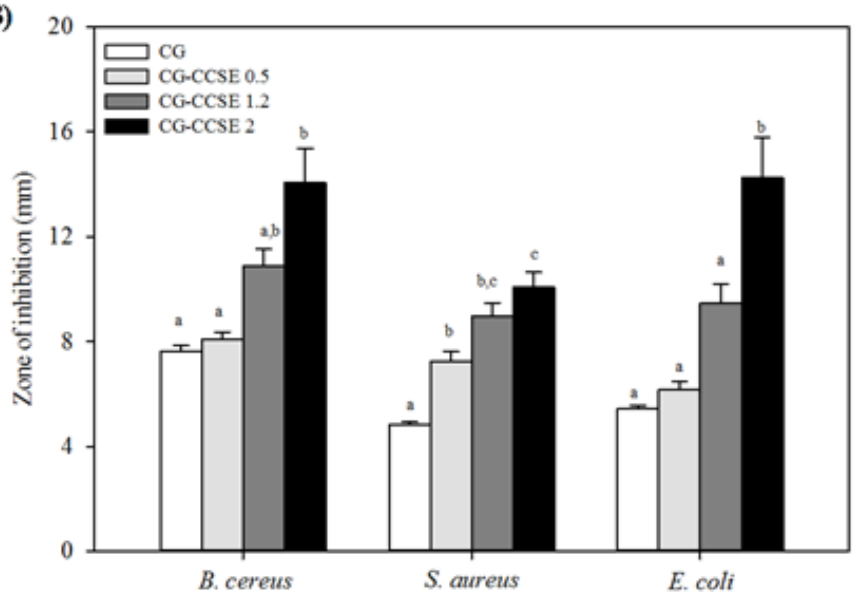

Figure 4 
(A) Scavenging activities of the CG-CCSE films on ABTS and DPPH radicals, (B) Inhibitory effects of CG-based film with different concentrations CCSE on four kinds of bacteria. Values are mean \pm SD $(n=3)$, a-d represent significant differences $(p<0.05)$.

\section{Figure 5}

(A) Biodegradability evaluation of CG-CCSE films. (B) Photographs of CG-CCSE films during the biodegradation test. Values are mean \pm SD $(n=3)$, a-d represent significant differences $(p<0.05)$.

\section{Figure 6}

Photographs of uncovered, CG, CG-CCSE 0.5, CG-CCSE 1.2 and CG-CCSE 2 films during the oxidation and rancidity of sunflower oil caused after sealed and stored at $50{ }^{\circ} \mathrm{C}$ for 28 days. 